\title{
Removing a metal stent using a string following endoscopic ultrasound-guided antegrade placement for pancreaticojejunostomy stricture
}

Temporary stent placement is effective for symptomatic pancreaticojejunostomy stricture (PJS). An endoscopic ultrasound (EUS)-guided approach is a useful salvage technique when balloon enteroscopy-assisted endoscopic retrograde cholangiopancreatography (ERCP) is unsuccessful [1 -4]. However, plastic stents are sometimes not sufficient to improve the stricture. Although covered self-expandable metal stents (CSEMS) may be useful for severe strictures, their removal after EUS-guided antegrade placement is challenging. Here, we report a successful case of removal of antegrade-placed CSEMS using a string via EUS-guided pancreaticogastrostomy.

A man in his $70 \mathrm{~s}$ developed acute recurrent pancreatitis due to PJS. As balloon enteroscopy-assisted ERCP failed, EUSguided antegrade placement of a CSEMS with string (BONASTENT M-Intraductal; Standard Sci Tech Inc., Seoul, Korea) [5] across the PJS, and plastic stent placement from the pancreatic duct to the stomach, were performed; the string was released into the stomach across the fistula.

At endoscopy 3 months later, a side-viewing scope was inserted to remove the stents ( $\mathbf{F i g} \mathbf{1} \mathbf{a}$ ). First, a guidewire was inserted into the pancreatic duct alongside the previously placed plastic stent and string. The stent was removed by grasping it with forceps through the scope, and the fistula was dilated using a dilation balloon. After removing the guidewire, the string was grasped with forceps and pulled toward the stomach ( Fig.1b). Subsequently, the proximal edge of the CSEMS was seen in the stomach ( $\triangleright$ Fig. 1 c). After reinsertion of the guidewire into the pancreatic duct across the CSEMS, the CSEMS was removed over the guidewire through the working channel by grasping it with a snare $(\triangleright$ Fig. $\mathbf{1}$ d, - Video 1). Finally, antegrade cleaning of
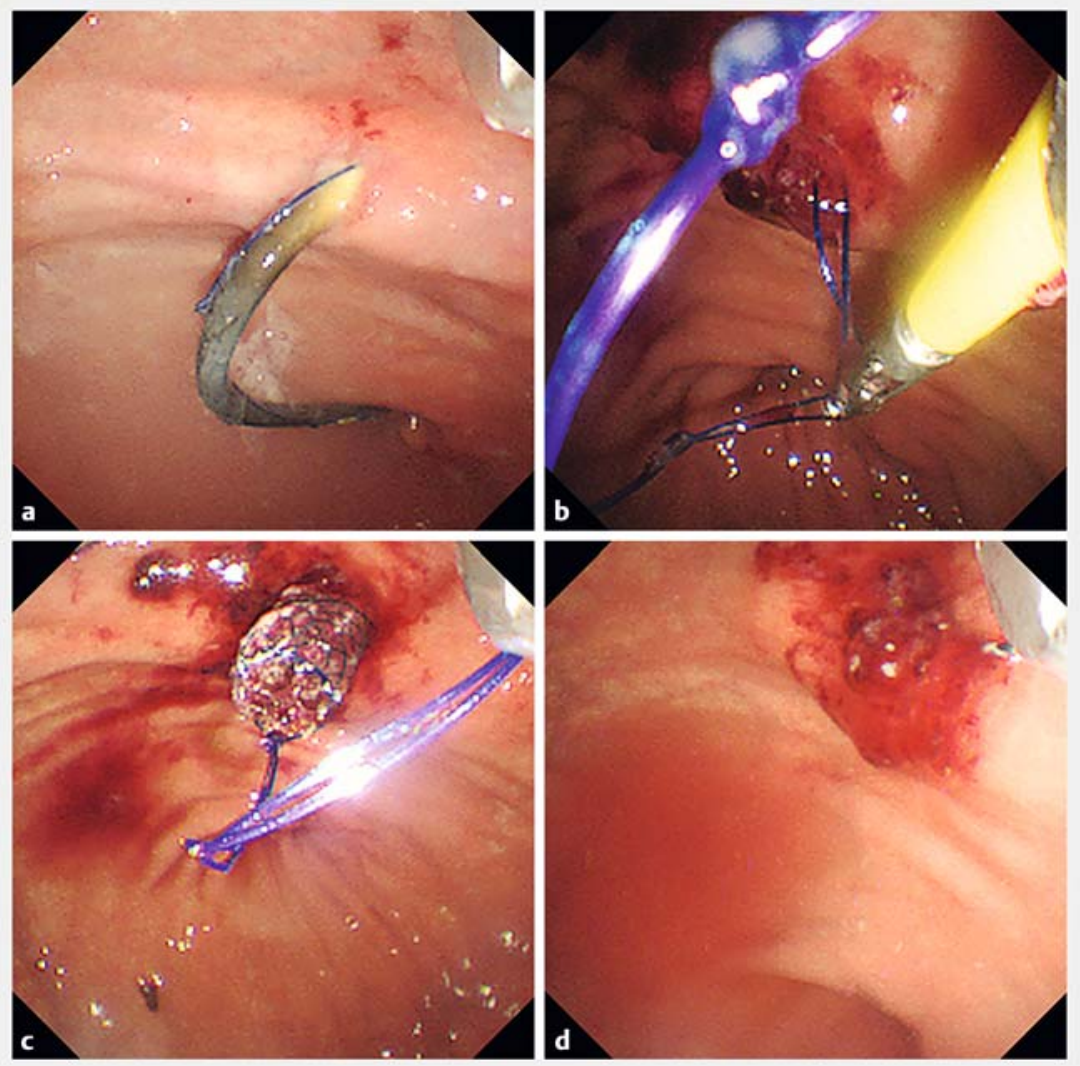

- Fig. 1 Endoscopic images. a A plastic stent and string in the stomach from the fistula. b After removal of the plastic stent, the string was grasped by forceps and pulled toward the stomach. c Subsequently, the proximal edge of the metal stent was seen in the stomach. d The metal stent was successfully removed by grasping it with a snare, with no adverse events.

the pancreatic duct using a retrieval balloon was performed, and complete resolution of the PJS was confirmed with pancreatogram. There were no adverse events, and no recurrence during followup.

CSEMS with a string can be removed simply through EUS-guided pancreaticogastrostomy. Antegrade placement and removal of it can be useful option for the treatment of PJS.

Endoscopy_UCTN_Code_CPL_1AK_2AG

\section{Competing interests}

None

The authors

Tadahisa Inoue, Mayu Ibusuki, Rena Kitano, Yuji Kobayashi, Kiyoaki Ito, Masashi Yoneda Department of Gastroenterology, Aichi Medical University, Aichi, Japan 


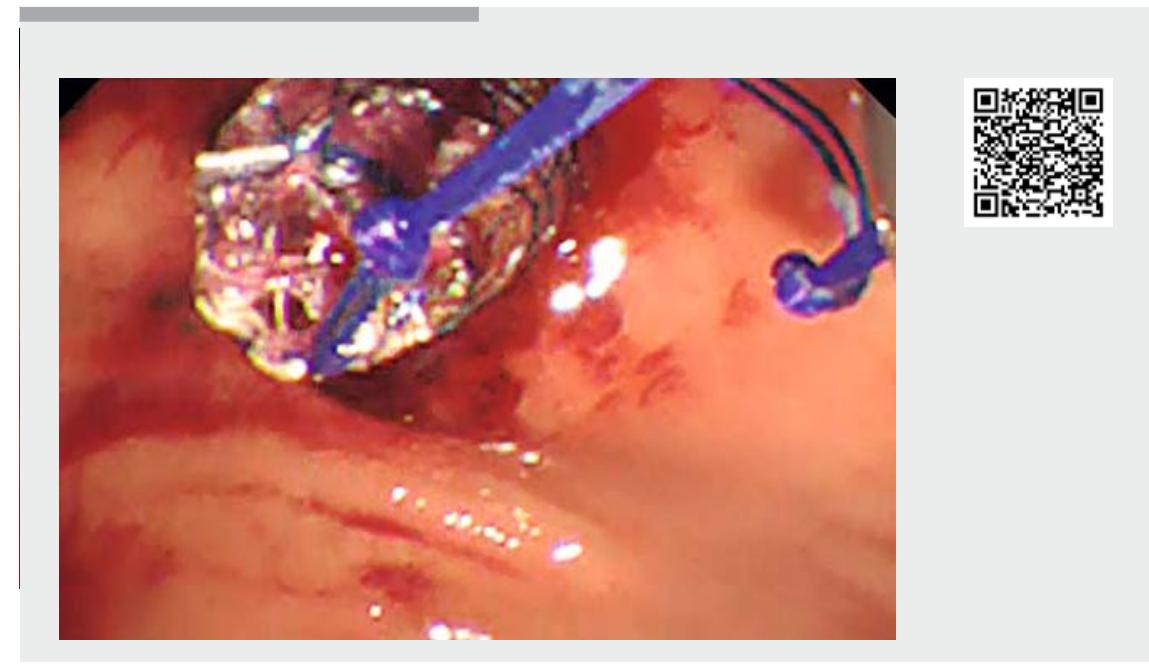

$\checkmark$ Video 1 At 3 months after endoscopic ultrasound-guided antegrade stent placement, we removed the stents. A covered self-expandable metal stent, which was placed for the pancreaticojejunostomy stricture, was successfully removed using a long string, without any adverse events.

\section{Corresponding author}

Tadahisa Inoue, MD, PhD

Department of Gastroenterology, Aichi Medical University, 1-1 Yazakokarimata, Nagakute, Aichi 480-1195, Japan Fax: +81-561-633208

tinoue-tag@umin.ac.jp

\section{References}

[1] Krafft MR, Nasr JY. Anterograde endoscopic ultrasound-guided pancreatic duct drainage: a technical review. Dig Dis Sci 2019. doi:10.1007/s10320-019-05495-9

[2] Chen YI, Levy M], Moreels TG et al. An international multicenter study comparing EUSguided pancreatic duct drainage with enteroscopy-assisted endoscopic retrograde pancreatography after Whipple surgery. Gastrointest Endosc 2017; 85: 170 - 177

[3] Matsunami Y, Itoi T, Sofuni A et al. Evaluation of a new stent for EUS-guided pancreatic duct drainage: long-term follow-up outcome. Endosc Int Open 2018; 6: E505E512

[4] Nakai Y, Kogure H, Koike K. Double-guidewire technique for endoscopic ultrasoundguided pancreatic duct drainage. Dig Endosc 2019; 31 (Suppl. 01): 65-66

[5] Moon JH, Choi HJ, Koo HC et al. Feasibility of placing a modified fully covered self-expandable metal stent above the papilla to minimize stent-induced bile duct injury in patients with refractory benign biliary strictures (with videos). Gastrointest Endosc 2012; 75: 1080-1085

\section{Bibliography}

DOI https://doi.org/10.1055/a-0989-2321

Published online: 21.8.2019

Endoscopy 2020; 52: E39-E40

(c) Georg Thieme Verlag KG

Stuttgart · New York

ISSN 0013-726X

\section{ENDOSCOPY E-VIDEOS}

https://eref.thieme.de/e-videos

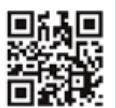

Endoscopy E-Videos is a free access online section, reporting on interesting cases and new

techniques in gastroenterological endoscopy. All papers include a high quality video and all contributions are freely accessible online.

This section has its own submission website at

https://mc.manuscriptcentral.com/e-videos 